\title{
Antituberculous drug resistance in western Canada (1993 to 1994)
}

\author{
RICHARD LONG BSc MD FRCPC FCCP, ANNE FANNING MD FRCPC, ROBERT COWIE MD, \\ VERNON HOEPPNER MD FRCPC, MARK FITZGERALD MB FRCP(I) FRCPC, \\ AND THE WESTERN CANADA TUBERCULOSIS GROUP* \\ University of Manitoba, Winnipeg, Manitoba; University of Alberta, Edmonton, Alberta; \\ University of Calgary, Calgary, Alberta; University of Saskatchewan, Saskatoon, \\ Saskatchewan; and University of British Columbia, Vancouver, British Columbia
}

R Long, A FANNing, R Cowie, V HoEpPNer, M FitzGERALD. Antituberculous drug resistance in western Canada (1993 to 1994). Can Respir J 1997;4(2):71-76.

OBJECTIVES: To estimate the magnitude of antituberculous drug resistance and identify prospectively the risk factors for its development in tuberculosis (TB) patients in western Canada over a one-year period.

DESIGN: Comparison of drug-resistant and nondrug-resistant cases of TB.

SETTING: Western Canada.

PATIENTS: All people with TB reported to the TB registries of Manitoba, British Columbia, Alberta and Saskatchewan between February 1, 1993 and January 31, 1994.

MAIN OUTCOME MEASURES: Drug susceptibility testing was performed in all cases of culture-positive tuberculosis. Patients at risk for human immunodeficiency virus (HIV) infection were serotested.

RESULTS: Of 534 culture positive cases of TB, 37 (6.9\%) were drug resistant. Odds ratios suggested that the risk of drug resistance was significantly higher among those with reactivation than among those with new disease, and among those born outside of Canada than among those born in Canada. Ninety per cent of the foreign-born patients with drug-resistant disease were from Asia. Of the 35 patients with drug resistance whose type of resistance was known, $76 \%$ had initial and $24 \%$ had acquired drug resistance. The initial resistance rate in Asian-born patients was 14\%. Most of the 37 drug-resistant cases were resistant to isoniazid $(68 \%)$, streptomycin (49\%) or both $(22 \%)$. Twelve (32\%) of the 37 cases were resistant to two or more first-line drugs. Of 14 patients who were HIV seropositive only one, a foreign-born patient, was drug resistant.

CONCLUSION: Antituberculous drug resistance is low among Canadian-born patients in western Canada, but not uncommon among those born outside Canada. Initial therapy of foreign-born patients should include four first-line drugs.

Key Words: Canada, Drug resistance, Tuberculosis

\section{Résistance aux agents antituberculeux dans l'Ouest canadien}

OBJECTIF: Estimer l'ampleur de la résistance aux agents antituberculeux et identifier de façon prospective les facteurs de risque pour son développement chez les patients tuberculeux dans l'Ouest canadien sur une période d'un an.

MODĖLE: Comparaison des cas de tuberculose pharmacorésistants et non pharmacorésistants.

CONTEXTE: L'Ouest canadien.

PATIENTS: Toutes les personnes atteintes de tuberculose signalées aux registres de la tuberculose du Manitoba, de la Colombie-Britannique, de l'Alberta et de la Saskatchewan entre le 1er février 1993 et le 31 janvier 1994.

PRINCIPALES MESURES DES RÉSULTATS: Les tests de susceptibilité aux médicaments ont été pratiqués dans tous les cas

voir page suivante

*The Western Canada Tuberculosis Group includes Dr E Hershfield, Director Tuberculosis Control, Manitoba; Dr RK Elwood, Director Tuberculosis Control British Columbia; the Directors of the Provincial Tuberculosis Laboratories, Drs A Kabani, T Martin, $J$ Talbot, D Kunimoto and W Black and their staff and the staff of the Provincial Tuberculosis Registries.

Correspondence and reprints: Dr R Long, RS330, Respiratory Hospital, 810 Sherbrook Street, Winnipeg, Manitoba R3A 1 R8. Telephone 204-787-2918, fax 204-787-1220,e-mail kharlos@cc.umanitoba.ca 
de tuberculose positifs à la culture. Les patients à risque pour le virus de l'immunodéficience humaine (VIH) ont été sérotestés.

RÉSULTATS: Des 534 cas de tuberculose positifs à la culture, 37 (6,9\%) étaient résistants aux médicaments. Le ratio d'incidence approché laissait à croire que le risque de pharmacorésistance était nettement plus élevé dans les cas de réactivation de la maladie que dans les nouveaux cas de tuberculose, et chez les individus nés à l'étranger plutôt que chez ceux nés au Canada. Quatre-vingt-dix pour cent des patients nés à l'étranger et démontrant une résistance aux antituberculeux provenaient d'Asie. Chez les 35 patients présentant une pharmacorésistance, et dont le type de résistance avait été identifié, il s'agissait d'une résistance primaire dans $76 \%$ des cas, et d'une résistance acquise dans $24 \%$ des cas. Le taux de résistance primaire chez les patients nés en Asie était de $14 \%$. La plupart des 37 cas pharmacorésistants l'étaient à l'isoniazide (68 $\%)$, la streptomycine (49\%) ou les deux (22\%). Douze (32\%) des 37 cas étaient résistants à deux ou plus de deux médicaments de première ligne. Des 14 patients séropositifs, seulement un, né àl'étranger, était résistant aux antituberculeux.

CONCLUSION: Dans l'Ouest canadien, les cas de résistance aux antituberculeux sont peu nombreux chez les patients nés au Canada mais ne sont pas rares chez les patients nés à l'étranger. La thérapie initiale des patients nés à l'étranger devrait donc inclure 4 médicaments de première ligne.
$\mathbf{I}_{\mathrm{p}}^{\mathrm{n}}$ a recent (1980 to 1989) retrospective survey from the province of Manitoba, $7.1 \%$ of patients with culture-positive tuberculosis (TB) had disease caused by organisms that were resistant to antituberculous drugs. Risk of drug resistance was found to be significantly higher among foreignborn patients, especially if they developed TB within the first five years of arrival in Canada (1). Although aboriginal persons (Canadian native Indian and Inuit) were not at increased risk of drug resistance, they were over-represented in a poorly compliant subgroup that became increasingly drugresistant over time. In the past decade the proportion of TB cases in foreign-born patients has increased in Canada, while the proportion in the aboriginal population has remained constant and the proportion in the Canadian-born nonaboriginal population has decreased (2). As well, regional differences in the proportion of TB cases in these three ethnic groups have developed; for example, in western Canada the majority of TB cases in British Columbia are found in the foreign born, while the majority of cases in Saskatchewan are found in aboriginal persons (2). In the present prospective survey we sought to determine the antituberculous drug resistance rate in western Canada, to confirm that the risk of drug resistance was higher in the foreign born compared with other ethnic groups and to ascertain whether regional differences in the ethnicity of TB patients might result from regional differences in drug resistance.

In the United States the strongest risk factor for human immunodeficiency virus (HIV)-associated multidrug-resistant TB (MDRTB) has been found to be place of residence, with most cases coming from New York City (3). If there was a problem with HIV-associated MDRTB in western Canada, one might expect to find it in Vancouver, British Columbia, where AIDS-related TB has been reported (4). In the present survey TB patients at risk for HIV were serotested.

\section{METHODS}

Demographic, clinical and mycobacteriological data were gathered on all cases of active TB diagnosed in residents of British Columbia, Alberta, Saskatchewan and Manitoba. Data were collected between February 1, 1993 and January 31, 1994 and were recorded prospectively by an on-site study nurse. Drug-resistant cases were identified through the records of the provincial mycobacteriology laboratories.

Demographic data: Age when diagnosed with TB, sex and ethnic status - foreign-born, aboriginal (registered [Treaty]
Indians, Métis and Inuit) and Canadian-born nonaboriginal were recorded. Treaty Indians are those registered with the Department of Indian and Northern Affairs according to the Indian Act of Canada. Canadians who were not Aboriginal were defined as 'others'. For foreign-born patients the country of origin and the date of arrival in Canada were noted.

Clinical data: For each case the type of disease (respiratory, nonrespiratory, both) and disease status (new active disease, reactivation) were recorded according to the Canadian $\mathrm{Tu}-$ berculosis Reporting System, Statistics Canada. A new active case is a case not previously reported. A reactivation is a recurrence of active disease in the same patient after a known period of inactivity. Patients from whom drug-resistant organisms were isolated were classified as having 'initial' drug resistance (no history of antituberculous drug use) or 'acquired' drug resistance (received antituberculous drugs in the past including prophylaxis for three months or more). Resistance was classified as 'unknown' in patients whose drug use history was unknown.

Resistance in patients with no history of prior antituberculous drug use was reported as 'initial' rather than 'primary' because it was anticipated that most of the drug-resistant patients would be foreign-born, precluding corroboration of their drug use history through records (5). 'Initial' resistance in Canadian-born Aboriginals and non-Aboriginals may be considered 'primary' (ie, resistance in a patient with no prior drug use with the information on drug use being collected in a standardized fashion and corroborated) because their drug use histories, in addition to being taken prospectively by a study nurse, were further corroborated through the records of the provincial tuberculosis registries.

Laboratory data: Isolates were processed with the radiometric system (BACTEC 460, Becton-Dickinson Diagnostic Instrument Systems, Maryland). Details of this method have been described previously (6). In each provincial mycobacterialogy laboratory the BACTEC system had been validated against the proportion method used by the Laboratory Centre for Disease Control, Ottawa, Ontario. Susceptibilities to four (isoniazid [INH], rifampin [RIF], ethambutol [EMB], and streptomycin $[\mathrm{SM}]$ ) and, in some cases, five (pyrazinamide [PZA]) drugs were performed in duplicate with the radiometric method. Drug concentrations used were as follows: INH $0.1 \mu \mathrm{g} / \mathrm{mL}$, RIF $2.0 \mu \mathrm{g} / \mathrm{mL}$, EMB $7.5 \mu \mathrm{g} / \mathrm{mL}$, SM $6.0 \mu \mathrm{g} / \mathrm{mL}$ and PZA $100 \mu \mathrm{g} / \mathrm{mL}$.

Patients identified at risk for HIV infection (when this 
TABLE 1

Culture results and resistance to antituberculous drugs among patients in western Canada with tuberculosis (TB) diagnosed from February 1, 1993 to January 31, 1994

\begin{tabular}{|c|c|c|c|}
\hline Variable & $\begin{array}{c}\text { Total } \\
\text { patients }\end{array}$ & $\begin{array}{c}\text { Patients with } \\
\text { drug-resistant } \\
\text { TB (\%) }\end{array}$ & $\begin{array}{c}\text { Odds ratio* } \\
(95 \% \\
\text { confidence } \\
\text { interval) } \\
\end{array}$ \\
\hline \multicolumn{4}{|l|}{ Age range (years) } \\
\hline 0 to 19 & 38 & $3(7.9)$ & 1.0 \\
\hline 20 to 39 & 180 & $16(8.9)$ & $1.1(0.3-4.1)$ \\
\hline 40 to 59 & 121 & $6(5.0)$ & $0.6(0.1-2.6)$ \\
\hline 60 or older & 192 & $12(6.3)$ & $0.8(0.2-2.9)$ \\
\hline Unknown/missing & 3 & 0 & \\
\hline \multicolumn{4}{|l|}{ Sex } \\
\hline Male & 303 & $15(5.0)$ & 1.0 \\
\hline Female & 231 & $22(9.5)$ & $2.0(1.0-4.0)$ \\
\hline \multicolumn{4}{|l|}{ Ethnic status } \\
\hline Aboriginal & 160 & $6(3.8)$ & 1.0 \\
\hline Foreign-born & 263 & $29(11.0)$ & $3.2(1.3-7.8)$ \\
\hline Other $^{\dagger}$ & 99 & $2(2.0)$ & $0.5(0.1-2.7)$ \\
\hline Unknown/missing & 12 & 0 & \\
\hline \multicolumn{4}{|c|}{ Time since arrival in Canada } \\
\hline Two years or less & 78 & $11(14.1)$ & 1.0 \\
\hline $\begin{array}{l}\text { Greater than } \\
\text { two years }\end{array}$ & 175 & $16(9.1)$ & $0.6(0.3-1.4)$ \\
\hline Unknown/missing & 10 & $2(20.0)$ & \\
\hline \multicolumn{4}{|l|}{ Disease status } \\
\hline New disease & 465 & $28(6.0)$ & 1.0 \\
\hline Reactivation & 62 & $9(14.5)$ & $2.4(1.0-5.5)$ \\
\hline Unknown/missing & 7 & 0 & \\
\hline \multicolumn{4}{|l|}{ Type of disease } \\
\hline Respiratory & 400 & $26(6.5)$ & \\
\hline Nonrespiratory & 115 & $11(9.6)$ & \\
\hline Both & 17 & 0 & \\
\hline Unknown/missing & 2 & 0 & \\
\hline
\end{tabular}

${ }^{*}$ First group for each variable is the reference category for calculating odds ratios. ${ }^{\dagger}$ Canadian-born nonaboriginal patients

survey was conducted this did not include patients with a diagnosis of TB) were serotested (screening, enzyme-linked immunoabsorbent assay, and confirmatory test, Western blot antibody test) after obtaining informed consent (7). Appropriate pre- and post-test counselling was performed.

Statistical analysis: Statistical differences in the proportion of patients with drug-resistant isolates were determined by the $\chi^{2}$ test. Results were considered significant at $\mathrm{P}<0.05$. Odds ratios (ORs) and $95 \%$ confidence intervals (CIs) were estimated (8).

\section{RESULTS}

Over the study period 534 cases of culture-positive tuberculosis were identified in residents of western Canada. Drug resistance occurred in isolates from 37 patients $(6.9 \% ; 29$ foreign-born, six aboriginal and two others).

Table 1 shows the results of culture and drug resistance by age, sex, ethnic status, years since immigration, disease status and type of disease. It also shows ORs and 95\% CIs to indicate the likelihood that a culture-positive case of tuberculosis would be resistant to one or more antituberculous drugs.
TABLE 2

Resistance to antituberculous drugs among tuberculosis patients from western Canada according to province and ethnic status

\begin{tabular}{|c|c|c|c|c|c|}
\hline \multirow[b]{2}{*}{ Province } & \multicolumn{5}{|c|}{ Ethnic status } \\
\hline & Aboriginal & $\begin{array}{c}\text { Foreign- } \\
\text { born }\end{array}$ & Other* & $\begin{array}{l}\text { Unknown } \\
\text { /missing }\end{array}$ & Tota \\
\hline \multicolumn{6}{|l|}{ Manitoba } \\
\hline Resistant & 0 & 1 & 0 & 0 & 1 \\
\hline Total & 51 & 24 & 15 & 2 & 92 \\
\hline Percentage & & 4.2 & & & 1.1 \\
\hline \multicolumn{6}{|l|}{ Saskatchewan } \\
\hline Resistant & 4 & 1 & 0 & 0 & 5 \\
\hline Total & 47 & 3 & 12 & 0 & 62 \\
\hline Percentage & 8.5 & 33.0 & & & 8.1 \\
\hline \multicolumn{6}{|l|}{ Alberta } \\
\hline Resistant & 0 & 9 & 1 & 0 & 10 \\
\hline Total & 16 & 80 & 24 & 0 & 120 \\
\hline Percentage & 0 & 11.3 & 4.2 & & 8.3 \\
\hline \multicolumn{6}{|c|}{ British Columbia } \\
\hline Resistant & 2 & 18 & 1 & 0 & 21 \\
\hline Total & 46 & 156 & 48 & 10 & 260 \\
\hline Percentage & 4.3 & 11.5 & 2.1 & & 8.1 \\
\hline \multicolumn{6}{|l|}{ Total } \\
\hline Resistant & 6 & 29 & 2 & 0 & 37 \\
\hline Total & 160 & 263 & 99 & 12 & 534 \\
\hline Percentage & 3.8 & 11.0 & 2.0 & & 6.9 \\
\hline
\end{tabular}

${ }^{*}$ Refers to Canadian-born nonaboriginal patients

ORs indicated that drug resistance was not influenced by age, time since arrival in Canada or type of disease. On the other hand, in a univariate analysis the risk of antituberculous drug resistance was significantly higher among foreign-born patients than Aboriginals or others (OR 3.2, 95\% CI 1.3 to 7.8). A borderline elevated risk of antituberculous drug resistance was seen between females versus males (OR 2.0, 95\% CI 1.0 to 4.0) and among those with reactivation versus new disease status (OR 2.4, 95\% CI 1.0 to 5.5). When a multiple logistic regression was performed on the same data, foreign-born ethnicity and reactivation disease status were confirmed to be independent risk factors for drug resistance.

The proportion of cases that were drug-resistant in each province was $1.1 \%$ in Manitoba, $8.1 \%$ in Saskatchewan, 8.3\% in Alberta and $8.1 \%$ in British Columbia; the proportion in Manitoba was significantly less than in the other three provinces $(\mathrm{P}<0.05)$ (Table 2). The most western provinces (Alberta and British Columbia) had the largest proportion of foreign-born TB patients (62\%), and the most eastern provinces (Manitoba and Saskatchewan) had the largest proportion of TB patients who were aboriginal (64\%). Drug resistance tended to be higher in British Columbia and Alberta (31 of 380, 8.2\%) than in Saskatchewan and Manitoba (six of 154, 3.9\%).

Of the foreign-born patients, 68\% (179 of 263) emigrated from five countries: China, India, Vietnam, Philippines and Hong Kong (Table 3). Most foreign-born patients who were drug-resistant (26 of 29, 90\%) were from these countries. Rates of initial resistance among foreign-born TB patients 


\section{TABLE 3}

Resistance to antituberculous drugs among foreign-born tuberculosis patients from western Canada according to country of origin

\begin{tabular}{lc}
\hline Country of origin & Total $^{\star}$ (all provinces) \\
\hline China & $6(5)$ \\
Resistant & $48(37)$ \\
Total & $13(14)$ \\
Percentage & \\
India & $6(6)$ \\
Resistant & $42(39)$ \\
Total & $14(15)$ \\
Percentage & \\
Vietnam & $8(5)$ \\
Resistant & $36(29)$ \\
Total & $22(17)$ \\
Percentage & \\
Philippines & $4(4)$ \\
Resistant & $33(31)$ \\
Total & $12(13)$ \\
Percentage & \\
Hong Kong & $2(2)$ \\
Resistant & $20(19)$ \\
Total & $10(11)$ \\
Percentage & \\
Total & $26(22)$ \\
Resistant & $179(155)$ \\
Total & $15(14)$ \\
Percentage &
\end{tabular}

${ }^{*}$ Figures in brackets refer to those not treated in the past

\section{TABLE 4}

Type of resistance among patients with drug-resistant tuberculosis by ethnic status

\begin{tabular}{|c|c|c|c|c|}
\hline \multirow[b]{2}{*}{ Ethnic status } & \multirow{2}{*}{$\begin{array}{c}\text { Number } \\
\text { of } \\
\text { patients } \\
\text { (total) }\end{array}$} & \multicolumn{3}{|c|}{ Type of resistance } \\
\hline & & $\begin{array}{l}\text { Initial* } \\
\text { (total) }\end{array}$ & $\begin{array}{c}\text { Acquired } \\
\text { (total) }\end{array}$ & $\begin{array}{l}\text { Unknown } \\
\text { (total) }\end{array}$ \\
\hline Aboriginal & $6(160)$ & $2(137)$ & $4(23)$ & $0(0)$ \\
\hline Foreign-born & $29(263)$ & $25(233)$ & $4(28)$ & $0(2)$ \\
\hline Other & $2(99)$ & $1(88)$ & $1(10)$ & $0(1)$ \\
\hline $\begin{array}{c}\text { Unknown/ } \\
\text { missing }\end{array}$ & 0 (12) & $0(7)$ & $0(1)$ & $0(4)$ \\
\hline Total & $37(534)$ & $28(465)$ & $9(62)$ & $0(7)$ \\
\hline
\end{tabular}

${ }^{*}$ Acquired Received antituberculous drugs in the past including prophylaxis if for three months or more. ${ }^{\dagger}$ Initial No history of antituberculous drug use. ${ }^{\ddagger}$ Refers to Canadian-born nonaboriginal

from each of these countries were China, five of $37(14 \%)$; India, six of $39(15 \%)$; Vietnam, five of 29 (17\%); Philippines, four of 31 (13\%); and Hong Kong, two of $19(11 \%)$.

More patients with drug resistance were classified as having initial resistance (76\%) than acquired resistance (24\%) (Table 4). There was no significant difference among the three ethnic groups as to the type of resistance. Patients who had received antituberculous drugs in the past were significantly more likely to be drug-resistant than those who had never received them $(15 \%$ versus $6 \%, \mathrm{P}<0.05)$.

Table 5 shows the distribution of resistance by individual drugs and combinations of drugs. Most common was resistance to INH (25 [67.6\%] of the patients with drug-resistant
TABLE 5

Type of resistance among patients with drug-resistant tuberculosis by drug*

\begin{tabular}{lccc}
\hline & \multicolumn{2}{c}{$\begin{array}{c}\text { Type of resistance } \\
\text { (percentage) }\end{array}$} \\
Drug & $\begin{array}{c}\text { Number of } \\
\text { patients }\end{array}$ & Initial & Acquired \\
\hline Isoniazid & 25 & $19(76.0)$ & $6(24.0)$ \\
Streptomycin & 18 & $13(72.2)$ & $5(27.8)$ \\
Ethambutol & 4 & $4(100.0)$ & \\
Rifampin & 4 & $1(25.0)$ & $3(75.0)$ \\
Pyrazinamide & 2 & $1(50.0)$ & $1(50.0)$ \\
Number of drugs & & & \\
$\quad$ One & 25 & $20(80.0)$ & $5(20.0)$ \\
$\quad$ Two or more & 12 & $8(66.7)$ & $4(33.3)$ \\
$\quad$ Total & 37 & $28(75.7)$ & $9(24.3)$ \\
\hline
\end{tabular}

${ }^{*}$ Drug susceptibility testing to pyrazinamide was performed on only 210 isolates

disease) and SM (18 [48.6\%]). In the majority of the patients with drug-resistant organisms (25 [67.6\%]), the isolates were resistant to only one drug. In four of the 12 cases (25\%) in which the isolates were resistant to two or more drugs, the isolates were resistant to both INH and RIF. Only two patients, both foreign-born, were shedding organisms resistant to three or more drugs. Both denied having received antituberculous drugs in the past. Of the 465 patients with culturepositive new active tuberculosis, initial resistance was found to the following drugs: INH 19 (4.1\%), SM 13 (2.8\%), EMB four $(0.9 \%)$ and RIF one $(0.2 \%)$. Drug susceptibility to PZA was performed on only 210 isolates, all from Manitoba and Alberta. One patient of the 210 tested was found to be resistant $(0.5 \%)$. Of patients who were serotested for HIV, 14 were found to be positive, 11 from British Columbia and three from the Prairie provinces. Only one, a foreign-born patient from Manitoba, was drug-resistant.

\section{DISCUSSION}

Over the study period we found that $6.9 \%$ of the patients in western Canada with culture-positive TB had disease that was resistant to antituberculous drugs. This proportion is very similar to the rate of resistance last reported in Manitoba (7.1\% in 1993) (1) and in the Canadian population overall (6.3\% reported in 1975) (9). Relative risk of drug resistance was 2.4 times greater among those with a reactivation than among those with new disease and 3.2 times greater among foreign-born patients than among Canadian-born. Previous surveys of antituberculous drug resistance in Canada suggested that the earlier TB developed in the foreign-born after their arrival in Canada the more likely the disease was to be drug-resistant $(1,9)$. In the present study there was a tendency for the risk of drug resistance to be higher among foreignborn patients who developed TB within their first two years in Canada than in those in whom it developed more than two years after immigration. However, the difference was not statistically significant, probably because of the smaller numbers in this survey.

Among foreign-born TB patients, $68 \%$ were from five 
Asian countries (China, India, Vietnam, Philippines and Hong Kong), reflecting the recent pattern of immigration to Canada, with increasing proportions of immigrants coming from Asian countries where TB morbidity rates are high (10). The majority of drug-resistant foreign-born patients (90\%) was from these five countries. Together the rate of initial resistance among them was $14 \%$, up from initial resistance rates of $7.6 \%$ (10) and $6.8 \%$ (11) reported in Asian immigrants to British Columbia in the early 1970s and 1980s, respectively.

Because $87 \%$ of the patients who developed drug-resistant TB after immigration to Canada denied being treated (initial resistance), we must assume that they have been infected with a drug-resistant strain in their country of origin or that their history was unreliable. That a substantial number of the foreign-born patients with disease resistant to the first-line antituberculous drugs denied previous treatment must be taken into account in the planning of antituberculous regimens for this group. It is recommended that foreign-born patients, particularly recent arrivals, be treated with four drugs until susceptibility testing allows a more individualized regimen. In most, but not all, this will ensure that at least two of the drugs will be effective when the bacterial population is large. Even this regimen would have been inadequate for two foreign-born patients who denied previous antituberculous drug use and yet were resistant to three or more first-line drugs. These cases illustrate the need for drug susceptibility testing of all isolates, particularly those from the foreign born.

On the other hand, according to the most recent American Thoracic Society/Centers for Disease Control and Prevention guidelines (12), rates of resistance in Canadian-born, aboriginal $(3.8 \%)$ and nonaboriginal $(2.0 \%)$ patients were sufficiently low (less than 4\%) to warrant the use of only three drugs in the initial treatment regimen, INH, RIF and PZA.

British Columbia and Alberta had a greater proportion of foreign-born TB cases (62\%), whereas Saskatchewan and Manitoba had a greater proportion of aboriginal TB cases (64\%). This regional difference in the ethnicity of TB patients may have contributed to the higher, though not statistically significant, rate of resistance in British Columbia and Alberta (8.2\%) compared with Saskatchewan and Manitoba (3.9\%). A more likely explanation for this difference in resistance rates between regions was the unusually low rate of resistance in Manitoba in the study year (1.1\%); a rate significantly less than that reported on average in the decade 1980 to $1989(7.1 \%)$, but nevertheless consistent with the variability in the rate of resistance seen over that period (4\% to $9 \%$, unpublished data).

Rates of initial resistance to INH (4.1\%) were higher than previously reported in Canada; rates in earlier surveys were $1.5 \%$ (1966) (13), 2.2\% (1978) (9) and 2.2\% (1993) (1). Rates of initial resistance to SM (2.8\%) were unchanged from previous surveys: $2.7 \%$ (1966) (13), $2.1 \%$ (1978) (9) and $2.1 \%$ (1993) (1).

Twelve (32\%) of the 37 patients with drug-resistant disease had isolates resistant to two or more first-line drugs. This high proportion of multiple-drug resistance supports a policy of treating all TB patients who are from a country with a high prevalence of drug resistance, have had previous treatment with antituberculous medications or have had known exposure to a drug-resistant case with four antituberculous drugs until the drug susceptibility test results are known [12]. Four (11\%) of the 37 drug-resistant patients were resistant to both INH and RIF. Outbreaks of disease resistant to these two drugs have been reported in association with HIV infection in the United States (3). These cases may be particularly hard to treat $(14,15)$. No MDRTB was found in association with HIV infection in our survey; only one HIV seropositive TB patient was drug-resistant and he was foreign-born, consistent with an earlier report of TB in the HIV infected in British Columbia (4), in which almost all were were Canadian-born nonaboriginal patients and none were drug-resistant.

ACKNOWLEDGEMENTS: The authors are very grateful to the many persons who assisted in the completion of this project. These include J Ross RN (Manitoba) and D McKenzie RN (British Columbia) for their technical assistance; the staff of the Laboratory Centre for Disease Control, Ottawa, Ontario; Michael Neuman, Senior Programmer, Respiratory Epidemiology Unit, Faculty of Medicine, University of Manitoba, Winnipeg, Manitoba; and Arlene Klassen for her preparation of the manuscript. This research was supported by a grant from the Lung Associations of Manitoba, British Columbia, Alberta and Saskatchewan.

\section{REFERENCES}

1. Long R, Manfreda J, Mendella L, Wolfe J, Parker S, Hershfield E. Antituberculous drug resistance in Manitoba, 1980-89. Can Med Assoc J 1993;148:1489-95.

2. Tuberculosis Statistics, 1993. Ottawa: Statistics Canada, May 1995. (Catalogue 82-220 annual)

3. Bloch A, Cauthen G, Onorato I, et al. Nationwide survey of drug-resistant tuberculosis in the United States. JAMA 1994;271:665-71.

4. Korzeniewska-Kosela M, FitzGerald M, Vedal S, et al. Spectrum of tuberculosis in patients with HIV infection in British Columbia: Report of 40 cases. Can Med Assoc J 1992;146:1927-34.

5. Chaulet P, Boulahbal F, Grosset J. Surveillance of drug resistance for tuberculosis control: why and how? Tuber Lung Dis 1995;76:487-92.

6. Scalcini M, Carre G, Jean-Baptiste M, et al. Antituberculous drug resistance in central Haiti. Am Rev Respir Dis 1990;142:508-11.

7. Phair JP, Wolinsky S. Diagnosis of infection with human immunodeficiency virus. Clin Infect Dis 1992;15:13-6.

8. Armitage P, Berry G. Statistical Methods in Medical Research, 2nd edn. London: Blackwell Science, 1987:453-84.

9. Eidus L, Jessamine AG, Hershfield ES, Helbecque DM. A national study to determine the prevalence of drug resistance in newly discovered previously untreated as well as in retreatment cases. Can J Public Health 1978;69:146-53.

10. Enarson D, Ashley JH, Grzybowski S. Tuberculosis in immigrants to Canada. Am Rev Respir Dis 1979;119:11-8.

11. Wang JS, Allen EA, Chao CW, Enarson D, Grzybowski S. Tuberculosis in British Columbia among immigrants from five Asian countries, 1982-85. Tubercle 1989;70:179-86.

12. Bass JB Jr, Farer LS, Hopewell PC, et al. Treatment of tuberculosis and tuberculosis infection in adults and children. Am J Respir Crit Care Med 1994;149:1359-74.

13. Armstrong AR. The prevalence in Canada of drug resistant tubercle bacilli in newly discovered untreated patients with tuberculosis. Can Med Assoc J 1966;94:420-5.

14. Goble M, Iseman MD, Madsen LA, Waite D, Ackerson L, Horsburgh CR Jr. Treatment of 171 patients with pulmonary tuberculosis resistant to isoniazid and rifampin. N Engl J Med 1993;328:527-32.

15. Telzak EE, Sepkowitz K, Alpert P, et al. Multidrug-resistant tuberculosis in patients without HIV infection. N Engl J Med 1995;333:907-11. 


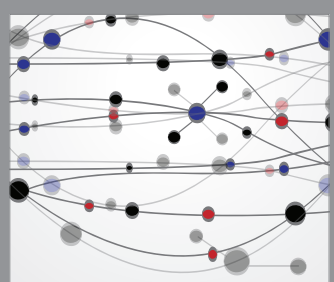

The Scientific World Journal
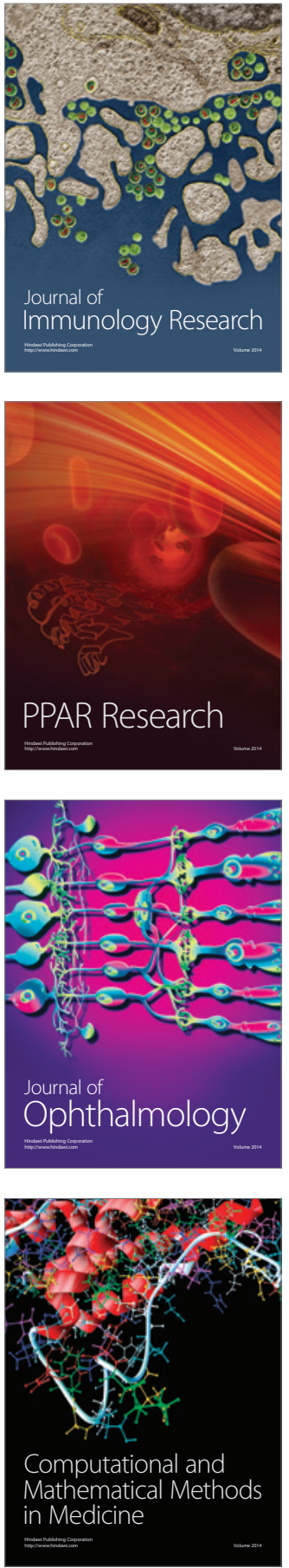

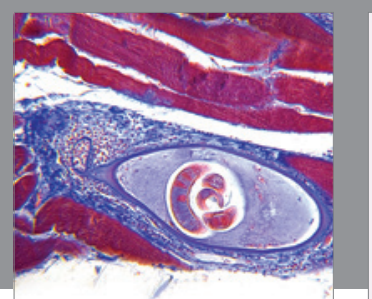

Gastroenterology Research and Practice

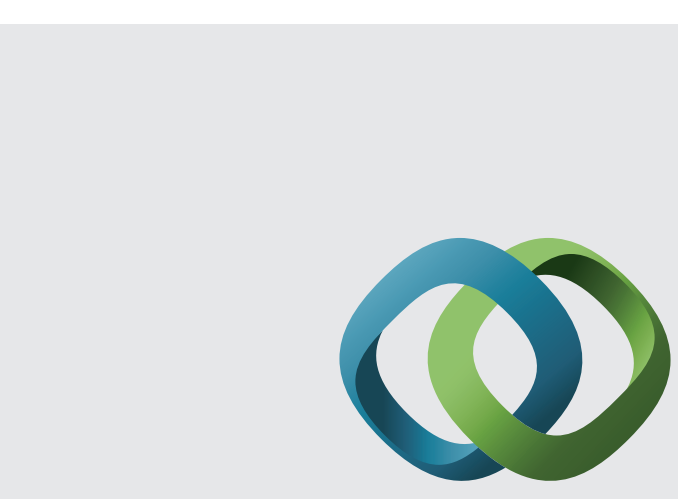

\section{Hindawi}

Submit your manuscripts at

http://www.hindawi.com

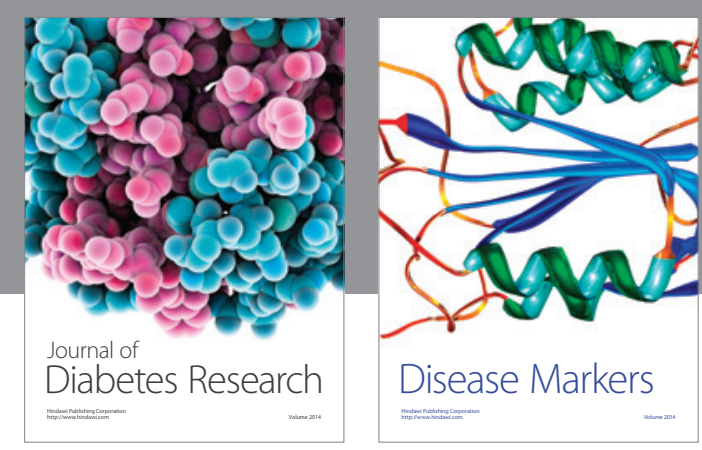

Disease Markers
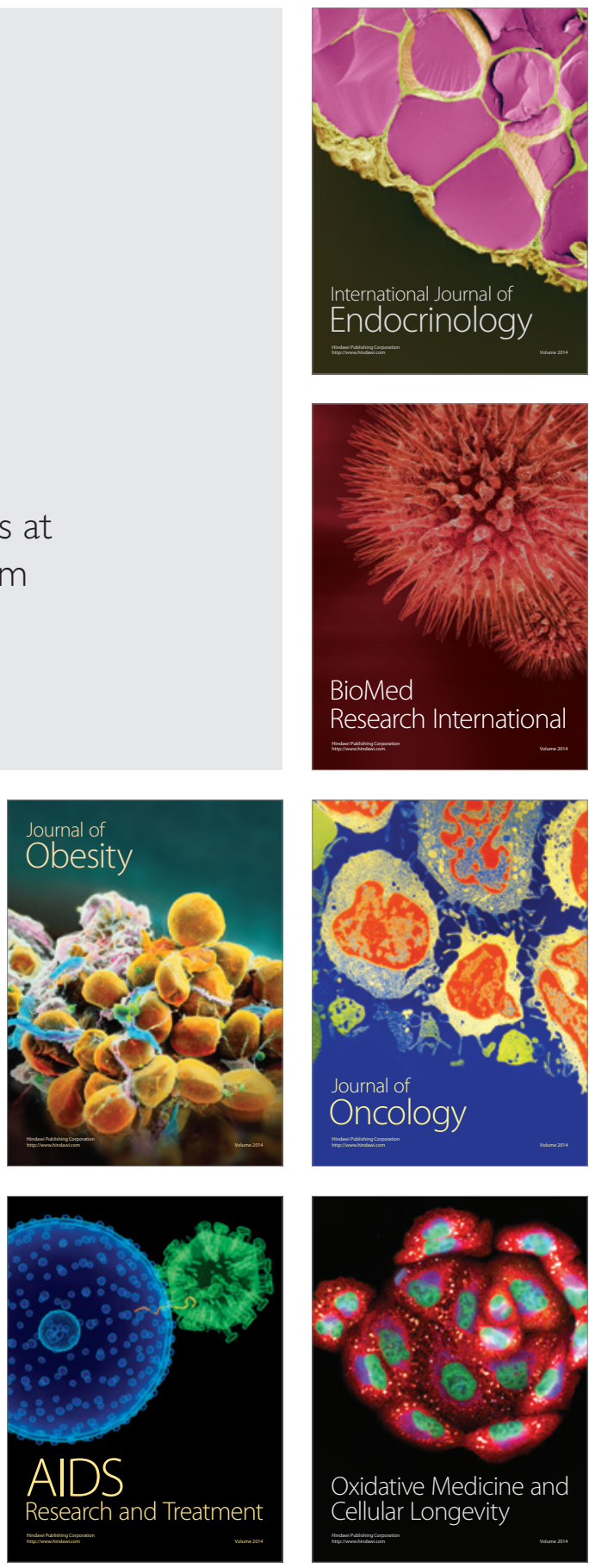